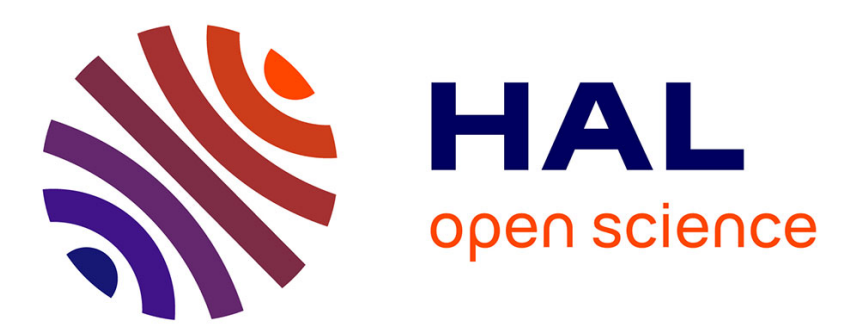

\title{
High sensitivity ultra-broad-band absorption spectroscopy of inductively coupled chlorine plasma
}

Daniil Marinov, Mickaël Foucher, Ewen Campbell, Mark Brouard, Pascal Chabert, Jean-Paul Booth

\section{- To cite this version:}

Daniil Marinov, Mickaël Foucher, Ewen Campbell, Mark Brouard, Pascal Chabert, et al.. High sensitivity ultra-broad-band absorption spectroscopy of inductively coupled chlorine plasma. Plasma Sources Science and Technology, 2016, 25 (3), pp.035019 10.1088/0963-0252/25/3/035019 . hal01346016

\section{HAL Id: hal-01346016 https: / hal.sorbonne-universite.fr/hal-01346016}

Submitted on 18 Jul 2016

HAL is a multi-disciplinary open access archive for the deposit and dissemination of scientific research documents, whether they are published or not. The documents may come from teaching and research institutions in France or abroad, or from public or private research centers.
L'archive ouverte pluridisciplinaire HAL, est destinée au dépôt et à la diffusion de documents scientifiques de niveau recherche, publiés ou non, émanant des établissements d'enseignement et de recherche français ou étrangers, des laboratoires publics ou privés. 


\title{
High sensitivity ultra-broad-band absorption spectroscopy of inductively coupled chlorine plasma.
}

\author{
Daniil Marinov $^{1}$, Mickaël Foucher ${ }^{1}$, Ewen Campbell², Mark Brouard ${ }^{2}$, Pascal \\ Chabert $^{1}$ and Jean-Paul Booth ${ }^{1}$
}

${ }^{1}$ Laboratoire de Physique des Plasmas (CNRS UPMC UPsud), Ecole Polytechnique, Route de Saclay 91128, Palaiseau

${ }^{2}$ The Department of Chemistry, University of Oxford, The Chemistry Research Laboratory, 12 Mansfield Road, OXFORD, OX1 3TA,United Kingdom

E-mail: daniil.marinov@1pp.polytechnique.fr

\begin{abstract}
We propose a method to measure the densities of vibrationally excited $\mathrm{Cl}_{2}(\mathrm{v})$ molecules in levels up to $\mathrm{v}=3$ in pure chlorine inductively coupled plasmas. The absorption continuum of $\mathrm{Cl}_{2}$ in the $250-450 \mathrm{~nm}$ spectral range is deconvoluted into the individual components originating from the different vibrational levels of the ground state, using a set of ab-initio absorption cross sections. It is shown that gas heating at constant pressure is the major depletion mechanism of the $\mathrm{Cl}_{2}$ feedstock in the plasma. In these line-integrated absorption measurements, the absorption by the hot (and therefore rarefied) $\mathrm{Cl}_{2}$ gas in the reactor centre is masked by the cooler (and therefore denser) $\mathrm{Cl}_{2}$ near the walls. These radial gradients in temperature and density make it difficult to assess the degree of vibrational excitation in the centre of the reactor. The observed line-averaged vibrational distributions, when analyzed taking into account the radial temperature gradient, suggest that vibrational and translational degrees of freedom in the plasma are close to local equilibrium. This can be explained by efficient VT relaxation between $\mathrm{Cl}_{2}$ and $\mathrm{Cl}$ atoms. Besides the $\mathrm{Cl}_{2}(\mathrm{v})$ absorption band, a weak continuum absorption is observed at shorter wavelengths, and is attributed to photodetachment of $\mathrm{Cl}^{-}$negative ions. Thus, line-integrated densities of negative ions in chlorine plasmas can be directly measured using broadband absorption spectroscopy.
\end{abstract}




\section{Introduction}

High density plasmas in chlorine and chlorine-based mixtures are widely used for etching of nanostructures in integrated circuit manufacturing [1]. Besides their technological importance, $\mathrm{Cl}_{2}$ plasmas have attracted a considerable attention as a model system for the study of the dynamics of electronegative molecular plasmas. Diagnostics techniques have been developed to measure the absolute densities of the most important neutral and charged species occurring in these plasmas: chlorine molecules [2,3], chlorine atoms in the ground and metastable states [4-7], electrons [8,9] and negative ions [10]. Combined with the measurements of the neutral gas temperature [11,12] this provides a comprehensive dataset for model validation. Numerical models of $\mathrm{Cl}_{2}$-containing plasmas have been proposed by several authors. Volume averaged (global) models of steady state and pulsed $\mathrm{Cl}_{2}$ plasmas have been developed in [13-17]. More sophisticated fluid and hybrid kinetic-fluid approaches have been adopted in [18-20].

Vibrational excitation is known to strongly affect the kinetics of molecular plasmas [21]. For example in chlorine, the cross section for dissociative electron attachment increases fast with the vibrational quantum number $\left(\sigma_{\mathrm{v}=0} / \sigma_{\mathrm{v}=1} / \sigma_{\mathrm{v}=2} / \sigma_{\mathrm{v}=3} \approx 1 / 4 / 8 / 12\right)$ [22]. Therefore in $\mathrm{Cl}_{2}$ plasmas, production of negative ions and dissociation of $\mathrm{Cl}_{2}$ may be substantially enhanced by vibrational excitation. Moreover, vibrationally excited $\mathrm{Cl}_{2}(\mathrm{v})$ could contribute significantly to the gas heating via VT relaxation processes with chlorine molecules and atoms [23]. Despite its potential importance, vibrational excitation in high density chlorine plasmas hasn't been properly characterized in previous experimental studies. This is partly because the detection of vibrationally excited chlorine molecules in the experiment is challenging especially at low gas pressures (in the mTorr range) typical for processing plasmas. In the present study, we demonstrate that broad-band absorption spectroscopy (BBAS) of $\mathrm{Cl}_{2}$ continuum between 250 and $450 \mathrm{~nm}$ can be used to characterise vibrational excitation in chlorine plasmas.

The well-known absorption continuum of $\mathrm{Cl}_{2}$ originates from the excitation of the ground state $\mathrm{Cl}_{2}$ to the unbound repulsive states $\left(C{ }^{1} \Pi_{1 \mathrm{u}}, A{ }^{3} \Pi_{1 \mathrm{u}}\right.$ and $\left.B{ }^{3} \Pi_{0+\mathrm{u}}\right)$, therefore leading to dissociation in all cases. Vibrational excitation in the ground state modifies the photodissociation process and leads to the appearance of new features in the absorption spectrum [24,25] resulting in a broadening of the absorption band [26]. In the present study, we use this effect as a diagnostic tool to measure the line-integrated densities of vibrationally excited (for levels up to $\mathrm{v}=3$ ) $\mathrm{Cl}_{2}$ molecules in a high-density inductively coupled plasma. The deconvolution of the broad absorption features into individual components originating from different vibrational levels of the ground state $\mathrm{Cl}_{2}$ is performed using a set of ab-initio absorption cross sections [24,27]. For the purpose of this study, the absorption cross sections from levels $\mathrm{v}=2,3$ were calculated using the time-dependent wave-packet method [28] previously used for $\mathrm{v}=0,1[24]$. 


\section{Experimental}

The experimental setup is shown schematically in Figure 1. The ICP reactor and the ultrabroad-band absorption diagnostics have been described previously [4,29]. Briefly, the discharge is sustained in a hard anodized aluminium chamber (cylinder, $10 \mathrm{~cm}$ height and 55 $\mathrm{cm}$ diameter) by a 4-turn planar spiral antenna placed on a top window made of alumina. The generator power $(13.56 \mathrm{MHz})$ is varied between 50 and $500 \mathrm{~W}$. The typical flow rate of $\mathrm{Cl}_{2}$ is $50 \mathrm{sccm}$ and the gas pressure is regulated between 5 and $80 \mathrm{mT}$ Torr by a throttle valve.

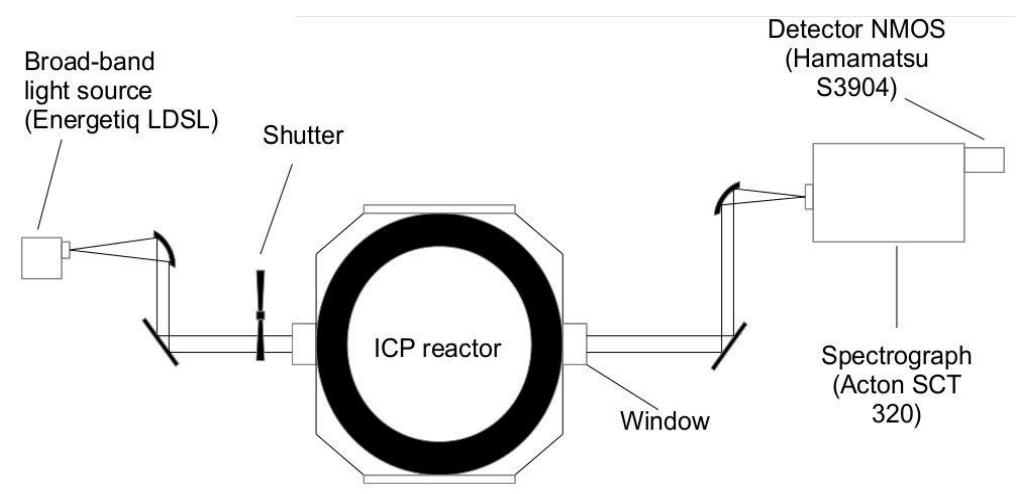

Figure 1 Experimental setup.

The broad band absorption is performed using a highly stable laser-driven light source (LDLS, Energetiq EQ-99) that provides very bright continuous radiation in the $200-2000$ $\mathrm{nm}$ spectral range. The output of the light source is collimated by a parabolic mirror and directed through the reactor (the optical path length inside the chamber is $57 \mathrm{~cm}$ ). After passing through the discharge at the midplane between the alumina window and the chuck, the light is focused (with another parabolic mirror) onto the entrance slit of an aberrationcorrected spectrograph (Acton Isoplane SCT-320, 300 1/mm grating) equipped with a linear photodiode array detector (Hamamatsu S-3904, 1024 pixels). The entire optical path is covered and purged with dry $\mathrm{N}_{2}$ in order to avoid accumulation of ozone produced by the UV radiation of the plasma and the lamp. The use of the stable light source in combination with achromatic optics ensures the stability of the baseline better than $5 \cdot 10^{-5}$ over a spectral range of $250 \mathrm{~nm}$ [29] which is a significant improvement compared to previous studies [2]. This ultra-broad-band and highly sensitive system was specially conceived for the investigation of broad, weak absorption features such as $\mathrm{Cl}_{2}$ at low pressure.

The experiment is automated using a Labview program which can switch the plasma on/off and operate a shutter in the light beam, in order to acquire spectra in four modes (to account for the emission of the plasma and the dark current of the detector)
$L_{1}(\lambda)$ plasma on, lamp on
$L_{2}(\lambda)$ plasma off, lamp on
$L_{3}(\lambda)$ plasma on, lamp off
$L_{4}(\lambda)$ plasma off, lamp off.

Signal accumulation is performed over several minutes (typically 100 cycles) to reach the optimum signal to noise ratio. The relative absorbance of the plasma with respect to the neutral $\mathrm{Cl}_{2}$ gas, $A^{\mathrm{r}}(\lambda)$, is then calculated using a standard expression: 


$$
\frac{I_{T}}{I_{0}}(\lambda)=\frac{L_{1}(\lambda)-L_{3}(\lambda)}{L_{2}(\lambda)-L_{4}(\lambda)}=\exp \left(-A^{r}(\lambda)\right)
$$

Since in this case the reference spectrum (plasma off, $L_{2}(\lambda)$ ) corresponds to a reactor full of undissociated $\mathrm{Cl}_{2}$, the observed relative absorbance spectrum, $A^{\mathrm{r}}(\lambda)$, is negative, representing the reduction in absorption due to the decrease in $\mathrm{Cl}_{2}$ when the plasma is on [2]. Therefore, the true absorption spectrum of the plasma $A(\lambda)$ is calculated from the sum of the observed relative absorbance spectrum, $A^{\mathrm{r}}(\lambda)$, and the absorbance $A^{\mathrm{Cl} 2}(\lambda)$ of undissociated $\mathrm{Cl}_{2}$ gas (no plasma) at a given pressure (measured in a separate experiment, in which a reference spectrum is taken with the reactor empty): $A(\lambda)=A^{\mathrm{r}}(\lambda)+A^{\mathrm{Cl} 2}(\lambda)$. This approach is taken because emptying the reactor of $\mathrm{Cl}_{2}$ for every reference spectrum would greatly slow down the data acquisition cycle, severely increasing the effect of slow temporal drifts in the lamp spectrum.

\section{Spectroscopy of $\mathbf{C l}_{2}$ and fitting of absorption spectra}

As mentioned above, the first absorption band of $\mathrm{Cl}_{2}$ arises from the excitation to unbound electronic states followed by dissociation. The vibration level dependent cross sections of this process for levels with $\mathrm{v}=0,1$ were calculated by Kokh et al. [27] in an ab-initio configuration interaction study. More recently, Campbell et al. [24] performed timedependent wave-packet calculations using a set of ab-initio potential energy curves from [27] to investigate the photo-dissociation dynamics of $\mathrm{Cl}_{2}(\mathrm{v}=0,1)$. For the purpose of the present study, these dynamic calculations were extended for vibrational levels up to $v=3$. It should be noted that these wave-packet calculations assume a constant transition dipole moment, and are therefore expected to be less accurate than the results of Kokh et al. [27].

The set of partial cross sections used to fit the experimental absorption spectra includes $\sigma_{v=1}(\lambda)$ from Kokh et al. [27] and $\sigma_{v=2,3}(\lambda)$ obtained using the dynamic wave-packet method. However, when these cross-sections were used (including $\sigma_{v=0}(\lambda)$ from Kokh et al.) to simulate a spectrum at $\mathrm{T}=298 \mathrm{~K}$, there were small but significant deviations from an accurate experimental cross section measured at $\mathrm{T}=298 \mathrm{~K}$ by Maric et al. [30] $\left(\sigma_{298 \mathrm{~K}}(\lambda)\right)$. Therefore, in order to increase the accuracy of the fit, instead of using the calculated cross section $\sigma_{\mathrm{v}=0}(\lambda)$ we use the experimental cross section of Maric et al. $\left(\sigma_{298 \mathrm{~K}}(\lambda)\right)$ which includes contributions from the low lying vibrational levels according to their equilibrium populations: $\sigma_{298 K}(\lambda) \approx 0.928 \cdot \sigma_{\mathrm{v}=0}(\lambda)+0.066 \cdot \sigma_{\mathrm{v}=1}(\lambda)+0.005 \cdot \sigma_{\mathrm{v}=2}(\lambda)$. Figure 2 shows the set of partial absorption cross sections used for spectra fitting. In order to allow for an offset of the experimental data, an additional function $\delta(\lambda)=$ const is added to the basis set. 


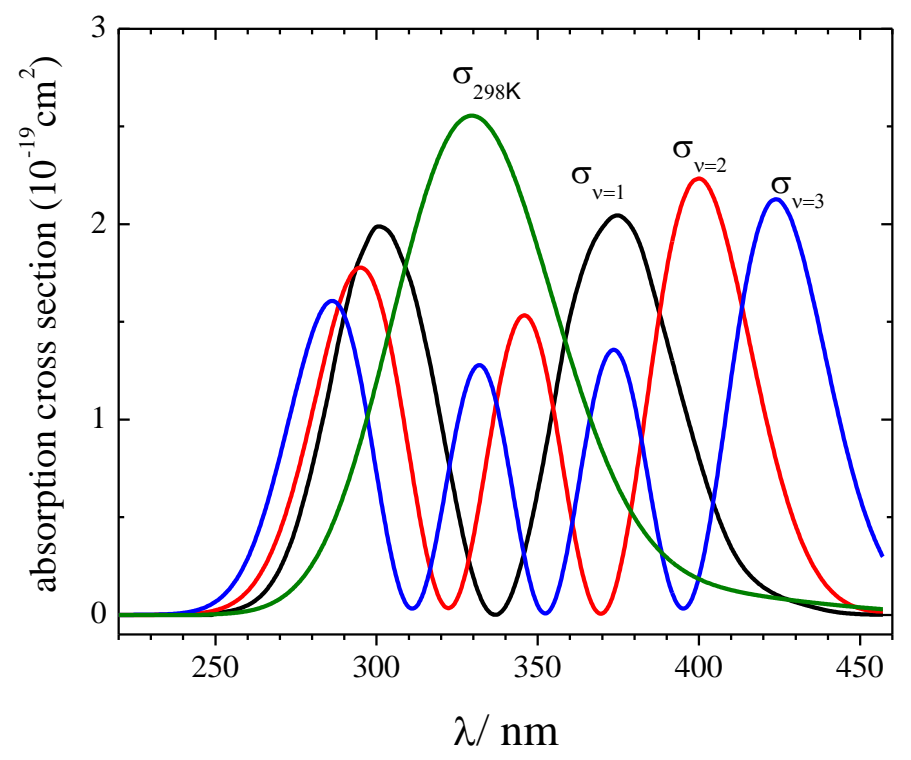

Figure 2 Partial absorption cross sections used for fitting of experimental data.

The experimental absorption spectra $A(\lambda)$ were fitted using the described set of cross sections $A(\lambda)=\hat{c}_{1} \sigma_{298 K}(\lambda)+\hat{c}_{2} \sigma_{\mathrm{v}=1}(\lambda)+\hat{c}_{3} \sigma_{\mathrm{v}=2}(\lambda)+\hat{c}_{4} \sigma_{\mathrm{v}=3}(\lambda)+\hat{c}_{5} \delta(\lambda)$

where the fit coefficients $\hat{c}_{i}$ are estimated using the least squares method. Line-integrated populations of $\mathrm{Cl}_{2}(\mathrm{v})$ are then calculated as follows:

$\left[\mathrm{Cl}_{2}(\mathrm{v}=0)\right]=0.928 \cdot \hat{c}_{1}$

$\left[\mathrm{Cl}_{2}(\mathrm{v}=1)\right]=0.066 \cdot \hat{c}_{1}+\hat{c}_{2}$

$\left[\mathrm{Cl}_{2}(\mathrm{v}=2)\right]=0.005 \cdot \hat{c}_{1}+\hat{c}_{3}$

$\left[\mathrm{Cl}_{2}(\mathrm{v}=3)\right]=\hat{c}_{4}$

This approach is numerically equivalent to deriving an experimental absorption spectrum for $\mathrm{v}=0, \sigma_{\mathrm{v}=0}(\lambda)$, from the experimental $\sigma_{298 \mathrm{~K}}(\lambda)$ by subtracting the calculated contributions of the higher vibrational levels. The vibrational temperature of $\mathrm{Cl}_{2}$ can be calculated from the ratio of the densities in the first two vibrational levels:

$T_{\mathrm{v}}=-E(\mathrm{v}=1) / \ln \left(\left[\mathrm{Cl}_{2}(\mathrm{v}=1)\right] /\left[\mathrm{Cl}_{2}(\mathrm{v}=0)\right]\right)$

where $E(\mathrm{v}=1)=790 \mathrm{~K}$ is the energy of the first vibrational level of $\mathrm{Cl}_{2}$ expressed in Kelvin. At equilibrium, $T_{\mathrm{v}}$ should to be equal to the kinetic gas temperature. However in nonequilibrium plasmas, kinetic and vibrational temperatures may differ considerably.

In order to confirm the validity of this fitting procedure, experiments with an externally heated gas cell were performed. A $10 \mathrm{~cm}$ long cylindrical quartz cell was filled with $\mathrm{Cl}_{2}$ at 5 Torr and was heated using a resistive heating tape. The temperature of the cell was measured using a thermocouple. Figure 3 shows the normalized absorption spectra of $\mathrm{Cl}_{2}$ measured at different cell temperatures. A significant broadening of the absorption band is observed as the 
cell temperature is increased. This is well reproduced by the fit, as illustrated in Figure 4 showing the experimental spectrum at $T_{\text {cell }}=650 \mathrm{~K}$ together with the corresponding fit.

Table 1 compares the temperature of the cell with the spectroscopically measured vibrational temperature $T_{\mathrm{v}}$. A very good overall agreement is obtained. The difference between $T_{\text {cell }}$ and $T_{\mathrm{v}}$ increases from $8 \mathrm{~K}$ to $40 \mathrm{~K}$ as the cell temperature is increased from $296 \mathrm{~K}$ to $700 \mathrm{~K}$. We attribute this discrepancy to the overall accuracy of the fit (and the cross sections) as well as to temperature gradients in the heated cell.

Fitting of the observed absorption spectra provides the (line-integrated) populations of the lower vibrational levels of $\mathrm{Cl}_{2}$. Figure 5 shows normalized vibrational distribution functions (VDFs) determined at different cell temperatures. As expected, the measured populations closely follow a Boltzmann distribution with the temperature parameter equal to the vibrational temperature of the first level $\left(T_{\mathrm{v}}\right)$. The measured population of $\mathrm{Cl}_{2}(\mathrm{v}=2)$ is systematically $30 \%$ lower than the expected Boltzmann population. We postulate that this discrepancy is due to the overestimation of the corresponding cross section $\sigma_{v=2}(\lambda)$ by the dynamic wave-packet method. Taking into account that our experimental absorption spectra from the heated gas cell are almost perfectly reproduced by the fit, we presume that the overall shape of partial cross sections is accurate and only the amplitude of $\sigma_{v=2}(\lambda)$ has to be adjusted. In the following data treatment, we apply a $30 \%$ correction to populations on $\mathrm{Cl}_{2}(\mathrm{v}=2)$ obtained from the fit of experimental absorption spectra.

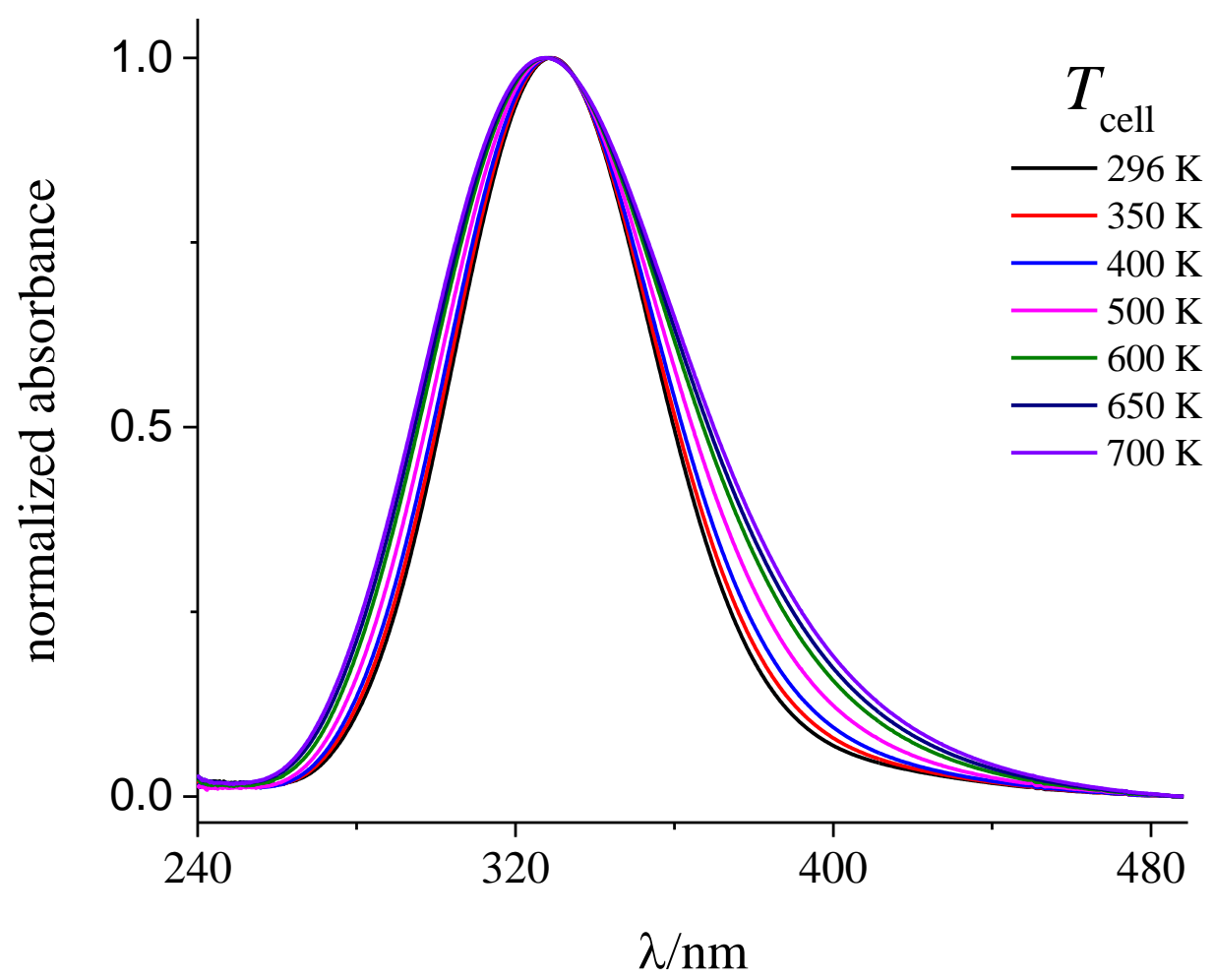

Figure 3 Normalized absorption spectra of $\mathrm{Cl}_{2}$ measured at different cell temperatures. 


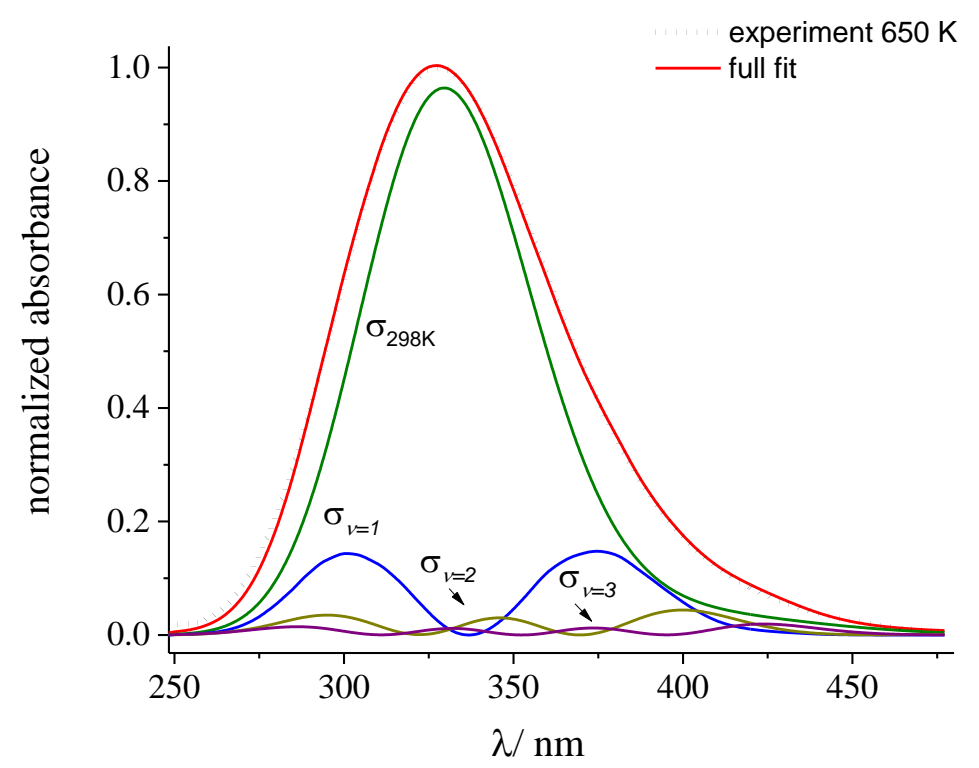

Figure 4 Normalized experimental absorption spectrum of $\mathrm{Cl}_{2}$ at $T_{\text {cell }}=650 \mathrm{~K}$ (dotted line) and the corresponding fit. Contributions of individual vibrational states are depicted separately.

\begin{tabular}{|l|l|l|l|l|l|l|l|}
\hline$T_{\text {cell }} / \mathrm{K}$ & 296 & 346 & 400 & 500 & 600 & 650 & 700 \\
\hline$T_{\mathrm{v}} / \mathrm{K}$ & 288 & 336 & 385 & 476 & 568 & 612 & 657 \\
\hline
\end{tabular}

Table 1 Comparison between the temperature of the cell and the vibrational temperature of $\mathrm{Cl}_{2}$ determined from the absorption measurements.

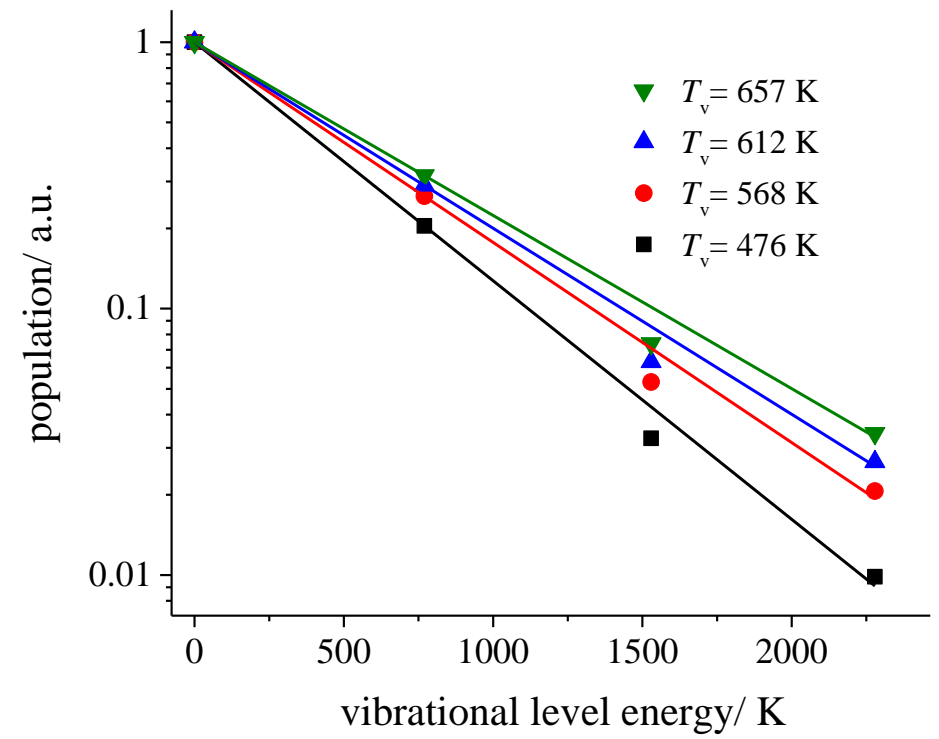

Figure 5 Normalized vibrational distributions measured at different cell temperatures (symbols). Bold lines represent Boltzmann distributions with the temperature parameter equal to $T_{\mathrm{v}}$.

In this section, we have shown that sensitive broad-band absorption spectroscopy can provide quantitative information on populations of vibrational levels of $\mathrm{Cl}_{2}$. In the following section, BBAS is applied to investigate the density of the different vibrational levels of $\mathrm{Cl}_{2}$ in a high density inductively coupled plasma. 


\section{Results and discussion}

Figure 6 shows the absorption spectra of chlorine plasma at 10 mTorr as a function of injected rf power. As the discharge power is increased the absorbance decreases due to depletion of the $\mathrm{Cl}_{2}$ feedstock, due to a combination of dissociation and gas heating (at constant pressure). This is accompanied by the appearance of an absorption continuum at the short-wavelength side of the spectrum. A closer inspection (see Figure 7) shows that additional step-like features (at $343 \mathrm{~nm}$ and $333 \mathrm{~nm}$ ) superimposed on the main $\mathrm{Cl}_{2}$ band become noticeable at higher rf power. We attribute these features to the continuum absorption due to photo-detachment of electrons from $\mathrm{Cl}^{-}$negative ions in the process $\mathrm{Cl}^{-}+h v \rightarrow$ $\mathrm{Cl}\left({ }^{2} \mathrm{P}_{3 / 2},{ }^{2} \mathrm{P}_{1 / 2}\right)$. The electron affinity of chlorine is $3.6 \mathrm{eV}$ which explains the threshold at 343 $\mathrm{nm}$. The second threshold at $333 \mathrm{~nm}$ is associated with the production of spin-orbit excited $\mathrm{Cl}\left({ }^{2} \mathrm{P}_{1 / 2}\right)$ upon the photo-detachment [31,32]. The photo-detachment cross section for $\mathrm{Cl}^{-}$ determined by Popp [31] was therefore included into the fit. Figure 7 shows an example of the fitted spectrum of the discharge at $500 \mathrm{~W}$ along with the separate contributions from $\mathrm{Cl}^{-}$ (corresponding to a line-averaged negative ion density of $(2 \pm 0.5) \cdot 10^{11} \mathrm{~cm}^{-3}$ ) and $\mathrm{Cl}_{2}$.

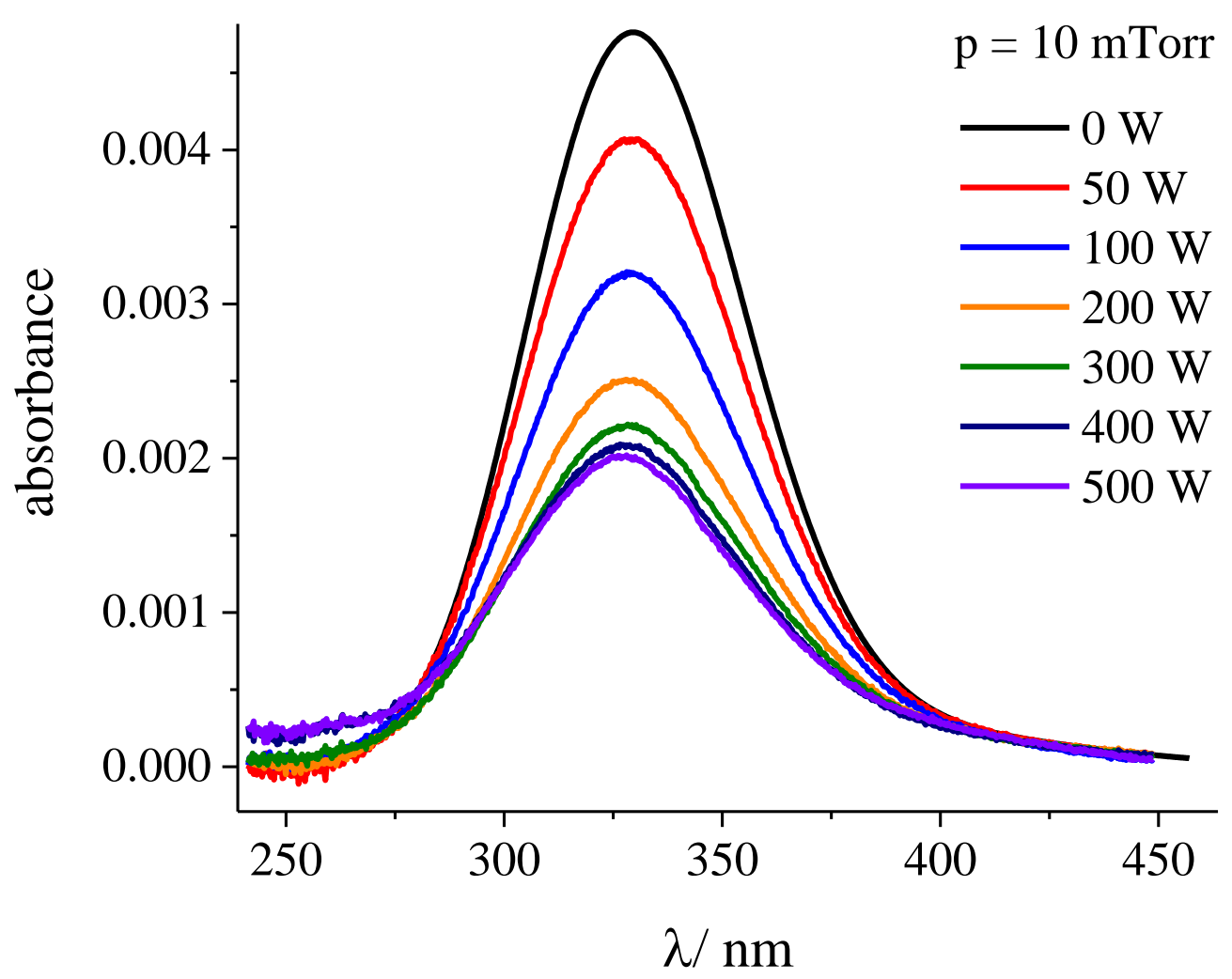

Figure 6 Absorption spectra of $\mathrm{Cl}_{2}$ plasma at $\mathrm{p}=10$ mTorr with injected power $\mathrm{P}=0-500 \mathrm{~W}$. 


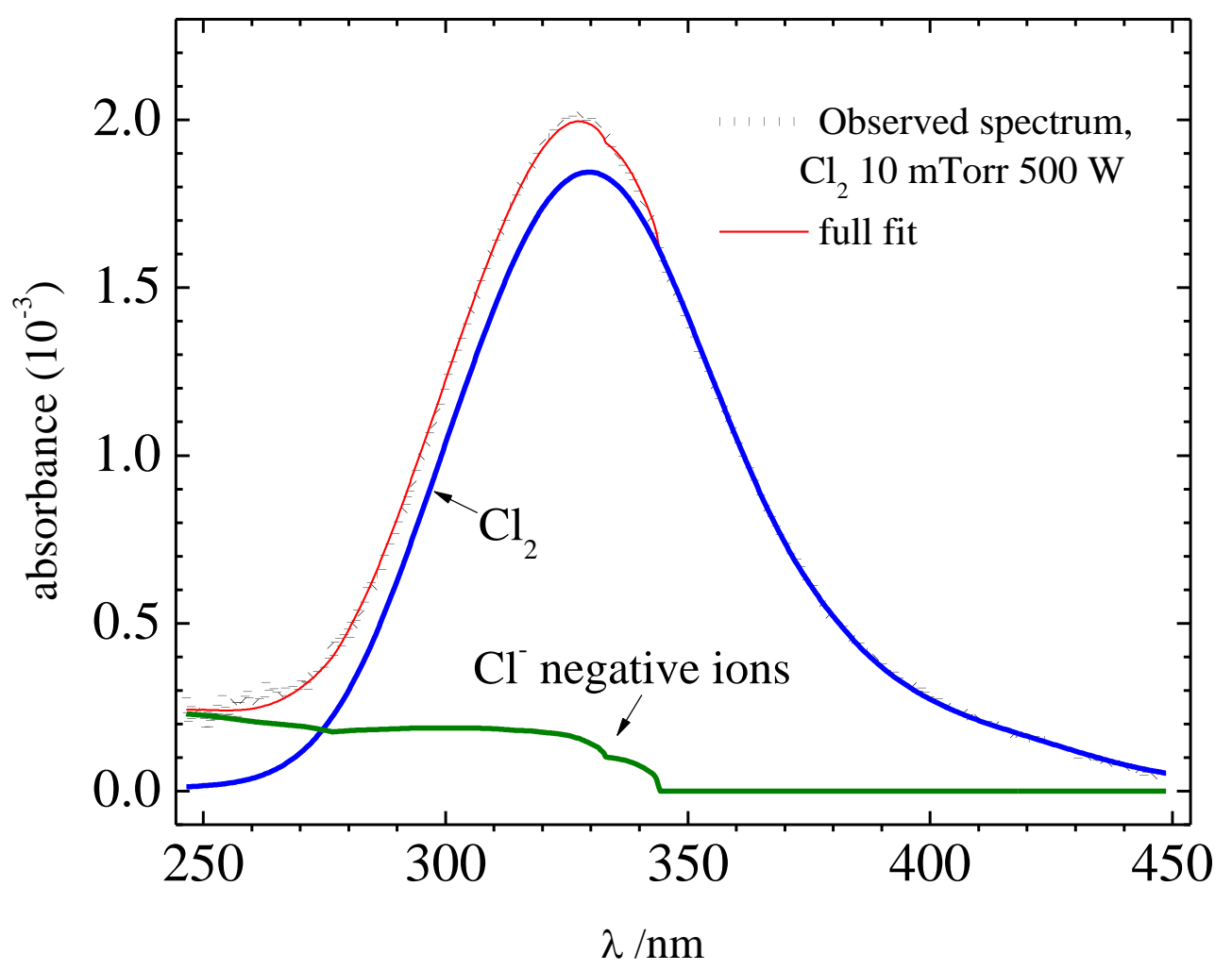

Figure 7 Absorption spectrum of $\mathrm{Cl}_{2}$ plasma ( $\left.\mathrm{p}=10 \mathrm{mTorr}, \mathrm{P}=500 \mathrm{~W}\right)$ and the corresponding fit. Contributions of $\mathrm{Cl}_{2}$ molecules and $\mathrm{Cl}^{-}$ions are shown separately. The best-fit value of the line-integrated density of negative ions is $\left[\mathrm{Cl}^{-}\right]=1.3 \cdot 10^{13} \mathrm{~cm}^{-2}$.

Fitting of the observed absorption spectra yields the line-integrated densities of $\mathrm{Cl}_{2}$ in each vibrational state in the discharge. Figure 8 shows the total molecular chlorine density (a sum over individual vibrational states) measured as a function of power and pressure. The density of chlorine molecules first decreases with rf power, but saturates at about $50 \%$ of the initial density (before plasma) for all studied pressures. In the discharge, dissociation and heating of the neutral gas are the main processes contributing to the depletion of the $\mathrm{Cl}_{2}$ feedstock $[2,15]$. Previous absolute measurements of atomic chlorine densities performed in the same reactor [4] showed that at $\mathrm{P}=500 \mathrm{~W}$ and $\mathrm{p}=5-50$ mTorr atomic chlorine density represents not more than $5-10 \%$ of the initial $\mathrm{Cl}_{2}$ density. Therefore, dissociation alone cannot explain the observed strong decrease of the $\mathrm{Cl}_{2}$ density. We conclude that gas heating (at constant pressure) is the major mechanism responsible for the depletion of $\mathrm{Cl}_{2}$ in the plasma under the studied conditions. The saturation at around $50 \%$ of the depletion can be attributed to the persistence of cold, undissociated $\mathrm{Cl}_{2}$ gas at the radial edges of the chamber, where the electron density is low, independent of the rf power. 


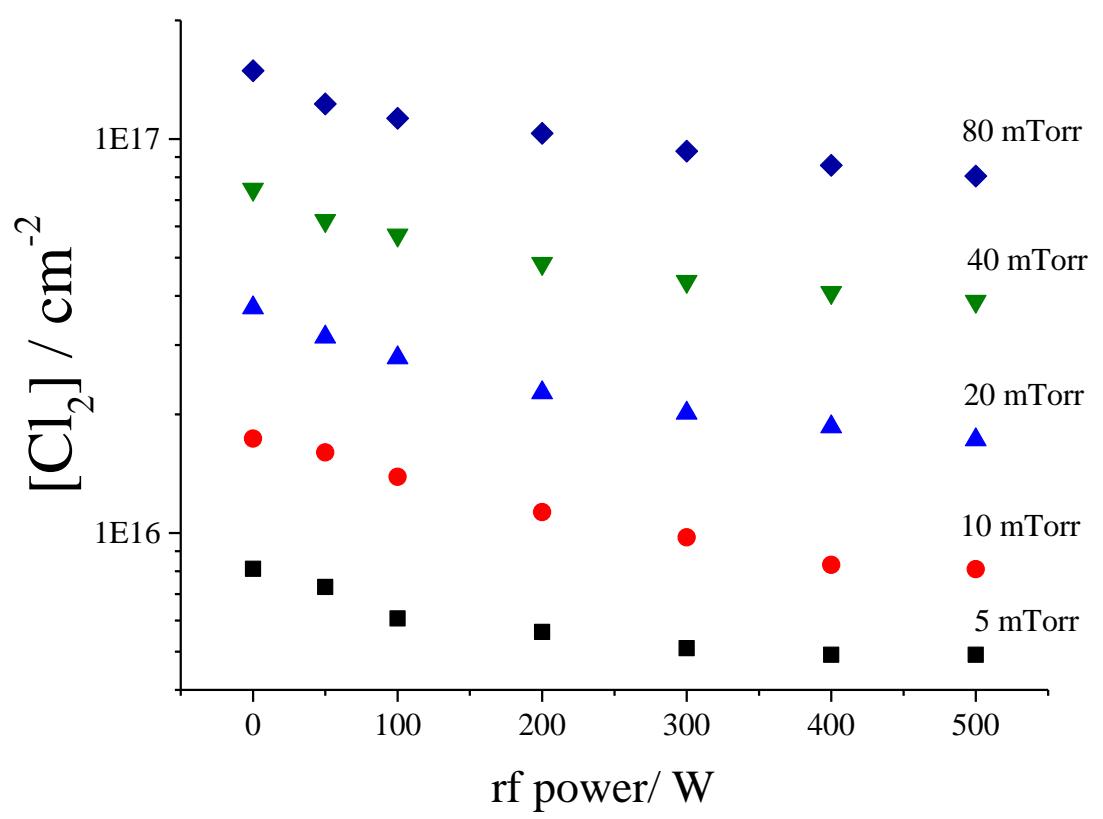

Figure 8 Line-integrated $\mathrm{Cl}_{2}$ density in the discharge ( $\mathrm{p}=5-80$ mTorr, $\mathrm{P}=0-500 \mathrm{~W}$ ).

Figure 9 shows the effective (i.e. derived from line-integrated densities on $v=0$ and $v=1$ ) vibrational temperature of $\mathrm{Cl}_{2}$ in the discharge as a function of power and pressure. The value of $T_{\mathrm{v}}$ increases with rf power, but the apparent vibrational heating remains surprisingly low, not exceeding $500 \mathrm{~K}$ at $\mathrm{P}=500 \mathrm{~W}$. This is much lower than the translational gas temperature as estimated from the Doppler broadening of $\mathrm{Ar} *$ transitions (5\% $\mathrm{Ar}$ added to $\mathrm{Cl}_{2}$ ) measured by tuneable diode-laser induced fluorescence (LIF) technique previously described in $[11,33]$, which reaches up to $1600 \mathrm{~K}$ in the centre of the reactor at the highest pressure and power. A more detailed description of the LIF results is beyond the scope of this paper and will be presented in an ongoing publication. The seeming discrepancy between LIF and BBAS results is a consequence of strong spatial gradients in the gas temperature: hot and strongly dissociated gas occupies the centre of the reactor while un-dissociated and much colder gas resides at the edge [4]. The density of hot $\mathrm{Cl}_{2}$ molecules in the reactor centre is strongly depleted and their contribution to the line-integrated absorption spectrum is relatively small. As a result, the absorption measurements are dominated by the cold periphery of the plasma.

The effect of the spatial non-uniformity of plasma parameters can be evidenced by analysing the populations of individual vibrational states of $\mathrm{Cl}_{2}$. Figure 10 shows line-integrated densities of $\mathrm{Cl}_{2}(\mathrm{v}=0-3)$ measured at $\mathrm{P}=500 \mathrm{~W}$ and $\mathrm{p}=5-80$ mTorr. The vibrational distribution function cannot be described by a single Boltzmann distribution. The apparent overpopulation of levels $\mathrm{v}=2$ and $\mathrm{v}=3$ can be explained by the contribution of the hot zone in the reactor centre. 


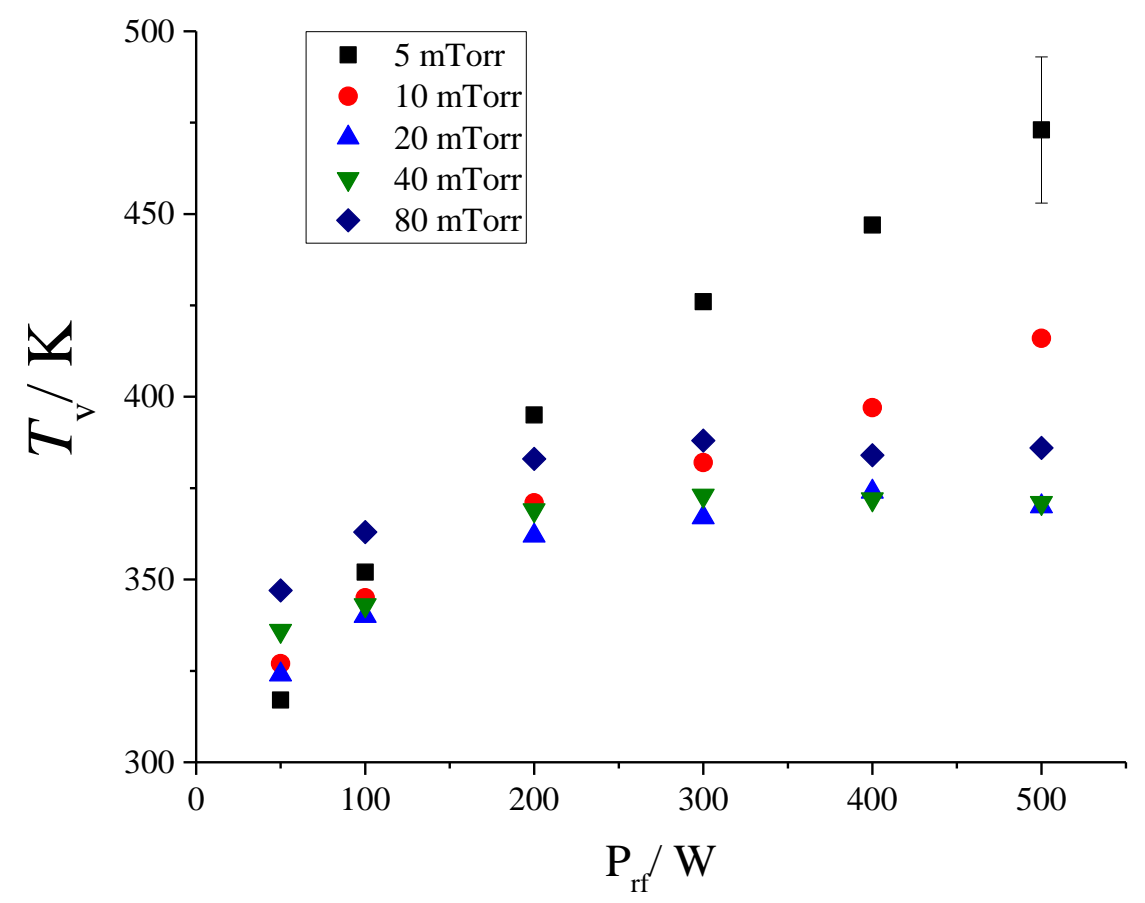

Figure 9 Effective vibrational temperature (from the ratio of populations in $\mathrm{v}=1 / \mathrm{v}=0$ ) of $\mathrm{Cl}_{2}$ as a function of the rf power measured at various gas pressures. An uncertainty of $( \pm 20 \mathrm{~K})$ is estimated in the $T_{\mathrm{v}}$ determination from the standard deviation of 7 independent measurements.

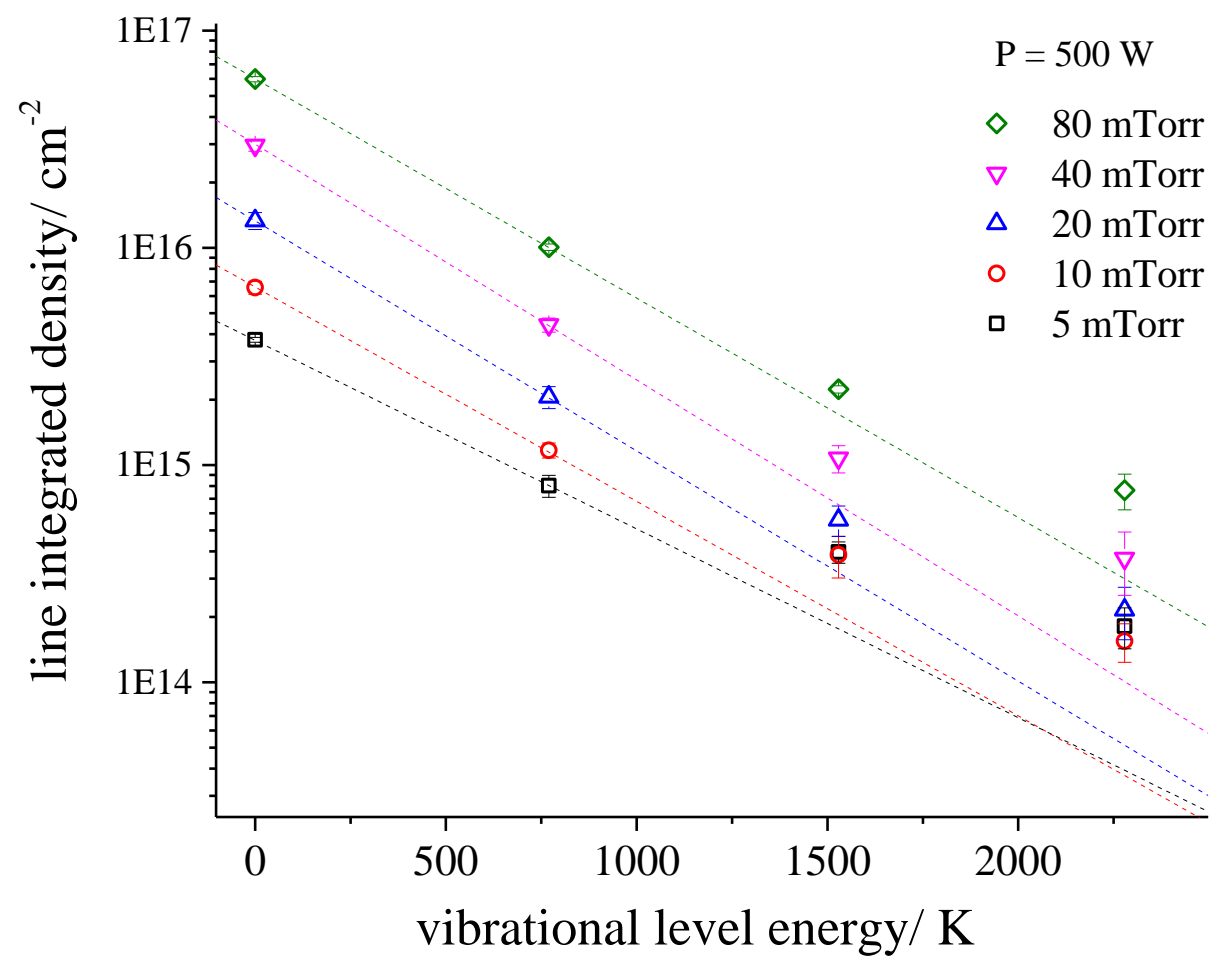

Figure 10 Line integrated densities of $\mathrm{Cl}_{2}(\mathrm{v}=0-3)$ measured at different pressures and a fixed rf power $\mathrm{P}=500$ W. Dashed lines represent Boltzmann distributions with the temperature equal to $T_{\mathrm{v}}$. Error bars correspond to the standard deviation of 7 independent measurements.

The non-equilibrium vibrational distributions of $\mathrm{Cl}_{2}(\mathrm{v})$ in the plasma may also be caused by electron impact excitation [34,35] and vibration-translation energy transfer processes between 
$\mathrm{Cl}_{2}$ (v) and $\mathrm{Cl}[36,37]$. It should be noted that these absorption measurements provide information both on the vibrational excitation and on the gas translational temperature in the discharge. The depletion of the total $\mathrm{Cl}_{2}$ density shown in Figure 8 is linked to the neutral gas heating provided that the dissociation fraction is independently measured. The vibrational level populations in Figure 10 represent the degree of vibrational excitation. So far we have made no assumption regarding the relation between the translational and the vibrational temperatures in the plasma. Detailed vibrational kinetic modelling [23] predicts that under the conditions of the present study, vibrational and translational degrees of freedom should be close to equilibrium owing to a very efficient $\mathrm{Cl}_{2}(\mathrm{v})$ and $\mathrm{Cl} \mathrm{VT}$ relaxation. Here we verify if the results of our BBAS measurements are compatible with the assumption of local equilibrium between vibrational and translational temperatures. Under this assumption, the line integrated densities of $\mathrm{Cl}_{2}(\mathrm{v})$ can be readily calculated if the radial profile of the gas temperature and the density of atomic $\mathrm{Cl}$ (the dissociation fraction) are known. This data is available from previous experimental and modelling studies performed in the same conditions as the present work $[4,23,33]$.

As a reference case we take chlorine ICP at $\mathrm{p}=10$ mTorr and $\mathrm{P}=500 \mathrm{~W}$. The gas temperature in the reactor centre close to $900 \mathrm{~K}$ was measured using $\mathrm{Ar}^{*}$ LIF. The spatial distribution of the gas temperature in the discharge has been recently modelled in [23] using the Hybrid Plasma Equipment Model (HPEM) [38]. Simulations predict a bell-shaped temperature radial profile that can be reasonably well approximated by a Gaussian with a FWHM of $28 \mathrm{~cm}$. As outlined in [23], the model fails to accurately reproduce the peak gas temperature at the reactor centre. Therefore in the following calculations, the calculated temperature profile is scaled to match with the measurements. Figure 11 (a) shows calculated radial profiles of $\mathrm{Cl}_{2}(\mathrm{v}=0-3)$ densities at the reactor mid-plane calculated assuming local thermodynamic equilibrium of the neutral species. In Figure 11 (b), the calculated and measured line-integrated populations are depicted. As one can see, the assumption of local thermodynamic equilibrium results in calculated line integrated densities that match the measurements within the experimental error.

To conclude, broad-band optical absorption measurements do not indicate any strong departure of the $\mathrm{Cl}_{2}$ vibrational distribution function from local thermodynamic equilibrium. This confirms model predictions in [23] regarding the equilibrium between vibrational and translational temperatures in $\mathrm{Cl}_{2}$ plasmas. It should be noted that in this study, only the populations of lower-lying vibrational states were measured. The sensitivity of our BBAS setup was not sufficient to detect highly vibrationally excited molecules, especially in the presence of cold gas at the radial reactor edges. Therefore, we cannot exclude the formation of non-equilibrium VDFs for high vibrational levels in the reactor centre where the plasma density is high. Such distributions of $\mathrm{O}_{2}$ (v) on levels up to $\mathrm{v}=18$ have been observed in our recent BBAS study of inductively-coupled plasmas in oxygen [29]. 
a)

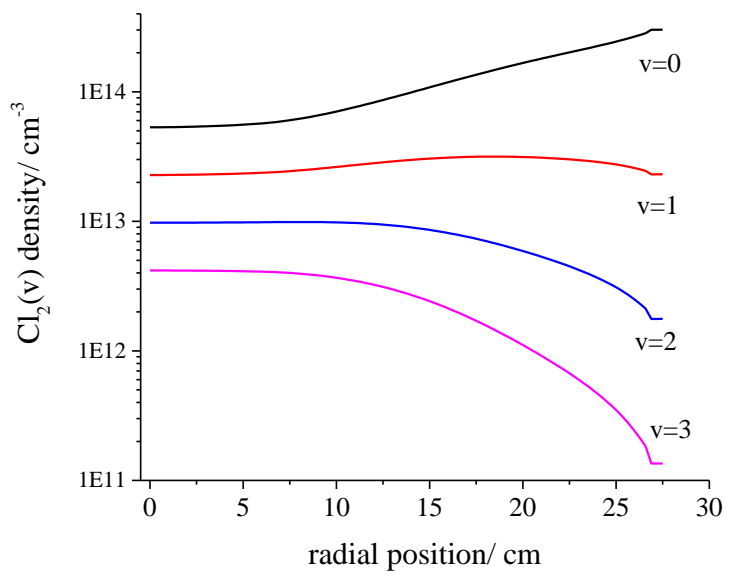

b)

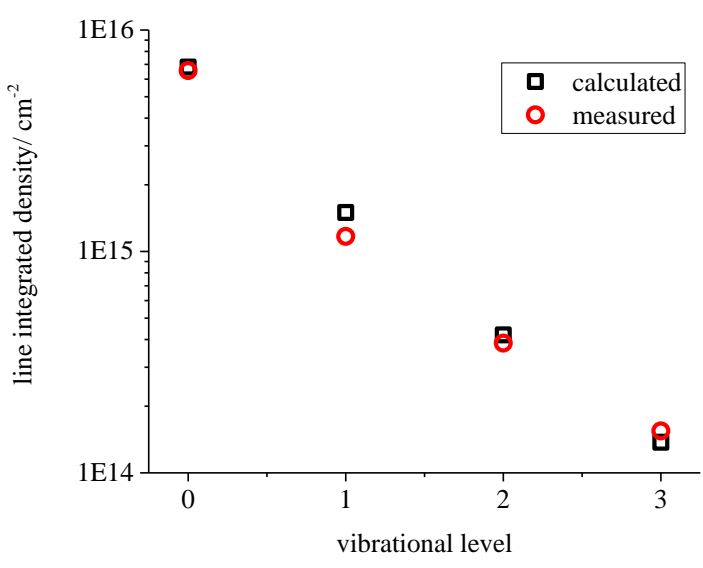

Figure 11 a) Radial profiles of densities of $\mathrm{Cl}_{2}(\mathrm{v}=0-3)$ calculated assuming local thermodynamic equilibrium of heavy plasma species. b) Comparison between measured and calculated line-integrated densities of $\mathrm{Cl}_{2}(\mathrm{v}=0-3)$.

In addition to the measurements of $\mathrm{Cl}_{2}(\mathrm{v})$ concentrations, BBAS allows the detection of $\mathrm{Cl}^{-}$ negative ions, a species which plays an important role in chlorine plasma kinetics and transport. In the conditions shown in Figure 7, the best-fit value of the line-integrated $\mathrm{Cl}^{-}$ density $(1.3 \pm 0.3) \cdot 10^{13} \mathrm{~cm}^{-2}$ is found, corresponding to an average density of $(2 \pm 0.5) \cdot 10^{11} \mathrm{~cm}^{-3}$. This is in a good agreement with the results of Fleddermann et al. [10] where $\mathrm{Cl}^{-}$densities up to $4 \cdot 10^{11} \mathrm{~cm}^{-3}$ were measured in a high density chlorine ICP. Therefore, high-sensitivity BBAS can be potentially used for direct measurement of absolute negative ion densities in chlorine plasmas. The advantage of this technique is that it requires no calibration, provided that available photo-detachment cross sections are accurate. The main limitation is that the peak absorbance of $\mathrm{Cl}^{-}$is very weak (below $2 \cdot 10^{-4}$ in this study) and it is hindered by a much stronger signal of $\mathrm{Cl}_{2}$. Therefore, $\mathrm{Cl}^{-}$can be detected only at low $\mathrm{Cl}_{2}$ pressures ( $\mathrm{p} \leq 10 \mathrm{mT}$ orr) and relatively high injected rf power, i.e. when the density of negative ions is sufficiently high compared to the $\mathrm{Cl}_{2}$ feedstock gas.

\section{Conclusions}

In the present study, an inductively coupled chlorine plasma was investigated by broad-band absorption spectroscopy in the $250-450 \mathrm{~nm}$ spectral range. Line-integrated densities of vibrationally excited $\mathrm{Cl}_{2}$ molecules in levels up to $\mathrm{v}=3$ were measured by fitting the $\mathrm{Cl}_{2}$ absorption band using a set of ab-initio absorption cross sections corresponding to individual vibrational levels of the ground state $\mathrm{Cl}_{2}$. The validity of the method was confirmed by measuring vibrational distributions of $\mathrm{Cl}_{2}$ in an externally heated gas cell.

We have shown that the depletion of the $\mathrm{Cl}_{2}$ feedstock occurs predominantly due to the strong gas heating in the plasma at a constant pressure. Regardless of high gas temperatures reaching $1600 \mathrm{~K}$ in the reactor centre, the effective vibrational temperature of $\mathrm{Cl}_{2}$ determined from the BBAS stays relatively low and does not exceed $500 \mathrm{~K}$. We attribute this difference to the radial non-uniformity of the plasma. Line integrated absorption measurements are dominated by the cold undissociated chlorine gas at the reactor periphery that hinders the 
contribution of the hot gas at the reactor centre. This limitation of the line-integrated absorption spectroscopy could be overcome by the use of optical probes that guide the broadband emission to the desired spatial location in the plasma.

In addition to $\mathrm{Cl}_{2}(\mathrm{v})$ measurements, the photodetachment continuum of $\mathrm{Cl}^{-}$negative ions was observed below $343 \mathrm{~nm}$. Owing to the excellent baseline stability of the absorption set-up over a wide spectral range partial absorbances of $\mathrm{Cl}^{-}$as low as $10^{-4}$ can be extracted from the total plasma absorption. That corresponds to the line-integrated density of negative ions of the order of $10^{13} \mathrm{~cm}^{-2}$ which is typical for large area high density processing plasmas. We have shown that BBAS is a versatile and sensitive diagnostics that can be used to measure densities and energy distributions of species in plasmas.

\section{Acknowledgments}

This work was performed within the LABEX Plas@par project, and received financial state aid managed by the Agence Nationale de la Recherche, as part of the programme "Investissements d'avenir" under the reference ANR-11-IDEX-0004-02 and ANR project CleanGRAPH(ANR-13-BS09-0019). The Authors are grateful to Dr. Daria Kokh for providing partial absorption cross sections for $\mathrm{Cl}_{2}(\mathrm{v}=0,1)$.

\section{References}

[1] Donnelly V M and Kornblit A 2013 Plasma etching: Yesterday, today, and tomorrow J. Vac. Sci. Technol. A Vacuum, Surfaces, Film. 31050825

[2] Neuilly F, Booth J-P and Vallier L 2002 Chlorine dissociation fraction in an inductively coupled plasma measured by ultraviolet absorption spectroscopy J. Vac. Sci. Technol. A Vacuum, Surfaces, Film. 20225

[3] Donnelly V M, Malyshev M V, Schabel M, Kornblit A, Tai W, Herman I P and Fuller N C M 2002 Optical plasma emission spectroscopy of etching plasmas used in Sibased semiconductor processing Plasma Sources Sci. Technol. 11 A26-30

[4] Booth J P, Azamoum Y, Sirse N and Chabert P 2012 Absolute atomic chlorine densities in a $\mathrm{Cl}_{2}$ inductively coupled plasma determined by two-photon laser-induced fluorescence with a new calibration method J. Phys. D. Appl. Phys. 45195201

[5] Marro F G and Graham W G 2008 Atomic chlorine two-photon LIF characterization in a $\mathrm{Cl}_{2}$ ICP plasma Plasma Sources Sci. Technol. 17015007

[6] Ono R, Takezawa K and Oda T 2009 Two-photon absorption laser-induced fluorescence of atomic oxygen in the afterglow of pulsed positive corona discharge $J$. Appl. Phys. 106 1-6

[7] Sirse N, Booth J P, Chabert P, Surzhykov A and Indelicato P 2013 Chlorine atom densities in the $\left(3 \mathrm{p}^{5}\right)^{2} \mathrm{P}_{1 / 2}^{0}$ excited spin-orbit state measured by two-photon absorption laser-induced fluorescence in a chlorine inductively coupled plasma J. Phys. D. Appl. Phys. 46295203

[8] Piejak R B, Al-Kuzee J, Braithwaite N S J 2005 Hairpin resonator probe measurements in RF plasmas Plasma Sources Sci. Technol. 14 734-43

[9] Malyshev M V., Donnelly V M, Colonell J I and Samukawa S 1999 Dynamics of 
pulsed-power chlorine plasmas J. Appl. Phys. 864813

[10] Fleddermann, C. B. and Hebner G A 1997 Negative ion densities in chlorine- and boron trichloride-containing inductively coupled plasmas J. Vac. Sci. Technol. A Vacuum, Surfaces, Film. 151955

[11] Cunge G, Ramos R, Vempaire D, Touzeau M, Neijbauer M and Sadeghi N 2009 Gas temperature measurement in $\mathrm{CF}_{4}, \mathrm{SF}_{6}, \mathrm{O}_{2}, \mathrm{Cl}_{2}$, and $\mathrm{HBr}$ inductively coupled plasmas J. Vac. Sci. Technol. A Vacuum, Surfaces, Film. 27471

[12] Donnelly V M and Malyshev M V. 2000 Diagnostics of inductively coupled chlorine plasmas: Measurements of the neutral gas temperature Appl. Phys. Lett. 772467

[13] Lee C 1995 Global model of $\mathrm{Ar}, \mathrm{O}_{2}, \mathrm{Cl}_{2}$, and $\mathrm{Ar} / \mathrm{O}_{2}$ high-density plasma discharges $J$. Vac. Sci. Technol. A Vacuum, Surfaces, Film. 13368

[14] Meeks E 1995 Effects of atomic chlorine wall recombination: Comparison of a plasma chemistry model with experiment J. Vac. Sci. Technol. A Vacuum, Surfaces, Film. 13 2884

[15] Thorsteinsson E G and Gudmundsson J T 2009 A global (volume averaged) model of a chlorine discharge Plasma Sources Sci. Technol. 19015001

[16] Kemaneci E, Carbone E, Booth J-P, Graef W, van Dijk J and Kroesen G 2014 Global (volume-averaged) model of inductively coupled chlorine plasma: Influence of $\mathrm{Cl}$ wall recombination and external heating on continuous and pulse-modulated plasmas Plasma Sources Sci. Technol. 23045002

[17] Despiau-Pujo E, Brihoum M, Bodart P, Darnon M and Cunge G 2014 Pulsed Cl 2 /Ar inductively coupled plasma processing: 0D model versus experiments J. Phys. D. Appl. Phys. 47455201

[18] Park S-K and Economou D J 1990 Analysis of low pressure rf glow discharges using a continuum model J. Appl. Phys. 683904

[19] Corr C S, Despiau-Pujo E, Chabert P, Graham W G, Marro F G and Graves D B 2008 Comparison between fluid simulations and experiments in inductively coupled argon/chlorine plasmas J. Phys. D. Appl. Phys. 41185202

[20] Subramonium P and Kushner M J 2002 Two-dimensional modeling of long-term transients in inductively coupled plasmas using moderate computational parallelism. II. Ar/Cl 2 pulsed plasmas J. Vac. Sci. Technol. A Vacuum, Surfaces, Film. 20325

[21] Gordiets B, Osipov A and Shelepin L 1988 Kinetic processes in gases and molecular lasers

[22] Kolorenč $\mathrm{P}$ and Horáček J 2006 Dissociative electron attachment and vibrational excitation of the chlorine molecule Phys. Rev. A 74062703

[23] Gibson Andrew, Gans Timo, Foucher Mickael, Marinov Daniil , Chabert Pascal, Guerra Vasco , Kushner Mark B J-P 2015 Modelling the infuence of neutral gas heating mechanisms on particle densities in inductively coupled chlorine discharges Bulletin of the American Physical Society 68th Annual Gaseous Electronics Conference (Honolulu, Hawaii: American Physical Society) p Volume 60, Number 9

[24] Campbell E K, Alekseyev a B, Balint-Kurti G G, Brouard M, Brown A, Buenker R J, Johnsen a J, Kokh D B, Lucas S and Winter B 2012 The vibrationally mediated 
photodissociation of $\mathrm{Cl}_{2}$ J. Chem. Phys. 137124310

[25] Gibson G, Rice O and Bayliss N 1933 Variation with Temperature of the Continuous Absorption Spectrum of Diatomic Molecules: Part II. Theoretical Phys. Rev. 44 193200

[26] Gibson G E and Bayliss N S 1933 Variation with temperature of the continuous absorption spectrum of diatomic molecules: Part I. Experimental, the absorption spectrum of chlorine Phys. Rev. 44 188-92

[27] Kokh D B, Alekseyev A B and Buenker R J 2004 Theoretical study of the UV photodissociation of $\mathrm{Cl}_{2}$ : Potentials, transition moments, extinction coefficients, and $\mathrm{Cl}^{* *} / \mathrm{Cl}$ branching ratio J. Chem. Phys. 120 11549-56

[28] Balint-Kurti G G, Orr-Ewing A J, Beswick J A, Brown A and Vasyutinskii O S 2002 Vector correlations and alignment parameters in the photodissociation of HF and DF $J$. Chem. Phys. 11610760

[29] Foucher M, Marinov D, Carbone E, Chabert P and Booth J-P 2015 Highly vibrationally excited $\mathrm{O}_{2}$ molecules in low-pressure inductively-coupled plasmas detected by high sensitivity ultra-broad-band optical absorption spectroscopy Plasma Sources Sci. Technol. 24042001

[30] Maric D, Burrows J P, Meller R and Moortgat G K 1993 A study of the UV-visible absorption spectrum of molecular chlorine J. Photochem. Photobiol. A Chem. 70 20514

[31] Popp H-P 1975 The radiation of atomic negative ions Phys. Rep. 16 169-217

[32] Mandl A 1976 Electron photodetachment cross sections of Cl- and Br- Phys. Rev. A 14 $345-8$

[33] Sirse N, Delivre Q, Booth J P and Chabert P 2012 Gas temperature measurement in Ar and $\mathrm{Ar}-\mathrm{Cl}_{2}$ based ICP discharge: Comparison between experiments and simulations 2012 Abstracts IEEE International Conference on Plasma Science (IEEE) pp 3P $135-3 \mathrm{P}-135$

[34] Ruf M-W, Barsotti S, Braun M, Hotop H and Fabrikant I I 2004 Dissociative attachment and vibrational excitation in low-energy electron collisions with chlorine molecules J. Phys. B At. Mol. Opt. Phys. 37 41-62

[35] Gregório J and Pitchford L C 2012 Updated compilation of electron-Cl 2 scattering cross sections Plasma Sources Sci. Technol. 21032002

[36] Thompson D L 1974 Monte Carlo classical dynamical study of the $\mathrm{Cl}+\mathrm{Cl}_{2}$ and $\mathrm{I}+\mathrm{I}_{2}$ systems: Vibrational relaxation and atom-exchange reactions J. Chem. Phys. 604557

[37] Guerra V and Loureiro J 1997 Electron and heavy particle kinetics in a low-pressure nitrogen glow discharge 6 361-72

[38] Rauf S and Kushner M J 1997 Argon metastable densities in radio frequency Ar, $\mathrm{Ar} / \mathrm{O}_{2}$ and $\mathrm{Ar} / \mathrm{CF}_{4}$ electrical discharges J. Appl. Phys. 822805 